\title{
LOGOTERAPIA: UMA VISÃO DA PSICOTERAPIA ${ }^{1}$
}

\author{
Logotherapy: a Vision of Psychotherapy \\ Logoterapia: una Visión de la Psicoterapia
}

PAUlo KroefF

\begin{abstract}
Resumo: Neste artigo são apresentadas algumas proposições centrais da logoterapia, como a preocupação com o sentido da vida e sua realização através de valores. São feitas algumas comparações da logoterapia com outros sistemas, como a psicanálise, a psicologia individual e o existencialismo. Examina-se sua evolução, que parte de uma proposição inicial de ser um aditivo à psicoterapia, até chegar a se apresentar como uma dentre as escolas de psicoterapia, e uma terapêutica específica no caso da neurose noogênica, finalizando por se oferecer também como um complemento às demais psicoterapias. São discutidos objetivos e formas de condução de sessões de logoterapia.
\end{abstract}

Palavras-chave: Logoterapia; Psicoterapia; Sentido de Vida; Valores; Neurose Noogênica.

\begin{abstract}
This paper presents some central propositions of logotherapy, such as the meaning of life and its realization through values. Some comparisons are made of logotherapy with other systems, such as psychoanalysis, individual psychology and existentialism. It examines its evolution, from an initial claim to be an additive to psychotherapy, evolving to present itself as one of the schools of psychotherapy, and a specific therapy in the case of noogenic neurosis, and finally, also, as a supplement to other psychotherapies. It is discussed goals and ways of conducting logotherapy sessions.

Keywords: Logotherapy; Psychotherapy; Meaning of Life; Values; Noogenic Neurosis.

Resumen: Este artículo presenta algunas proposiciones centrales de la logoterapia, como la preocupación por el significado de la vida y su realización a través de los valores. Se presentan algunas comparaciones de la logoterapia con otros sistemas, como el psicoanálisis, la psicología individual y el existencialismo. Se examina su evolución, que parte de una proposición inicial de ser un aditivo a la psicoterapia, hasta presentarse como una de las escuelas de psicoterapia, y un tratamiento específico en el caso de neurose noogénica y, finalmente, por ofrecerse también como complemento de otras psicoterapias. Son discutidos objetivos y formas de conducción de sesiones de logoterapia.

Palabras-clave: Logoterapia; Psicoterapia; Sentido de la Vida; Valores; Neurose Noogénica.
\end{abstract}

\section{Introdução}

Viktor Frankl, o criador da logoterapia, aceitou a indicação de outros autores de situar sua teoria dentro da psicologia humanista ou da psiquiatria existencial (Frankl, 1983). Contudo, apesar de não negar esta maior identificação, não deixou de marcar também diferenças com essas orientações. Um exemplo disso, com relação ao humanismo, é a crítica que Frankl faz quanto à utilização do termo auto-realização, o qual tenderia a enfatizar demasiadamente a possibilidade de a pessoa se realizar em si mesma. Para a logoterapia, esta realização só ocorre após o sentido de vida ser concretizado, o que é possível quando o indivíduo sai de si, ao encontro de alguém ou de algo que está no mundo. Por isto, Frankl prefere falar de autotranscendência, como pré-requisito para a realização. Outra diferença, agora com os existencialistas, é com relação ao sentido da vida. Alguns afirmam que a vida carece de sentido, sendo em si mes-

1 Trabalho originalmente apresentado no V Congresso Brasileiro de Análise Existencial - Logoterapia, realizando em Curitiba (PR), novembro, 2010. ma um absurdo que, para ser suportado, necessita que se "invente" um sentido para a vida. Já Frankl afirma que a vida sempre tem sentido, o qual está no mundo, sendo simplesmente necessário que este sentido seja "descoberto" pela pessoa.

Frankl também assinalou diferenças com a psicanálise e a psicologia individual. Ele não desconsiderava o que essas duas escolas pretendiam levar à consciência do homem - os instintos e a responsabilidade com os laços sociais, respectivamente -, mas alertava também para a necessidade de trazer à consciência o sentido e os valores:

Enquanto a psicanálise vê o neurótico só de um lado, como dominado pelo princípio do prazer, ou seja, a vontade orientada ao prazer, e a psicologia individual como determinado pelo afã de prestígio, ou seja, a vontade de poder, a nova psicoterapia vê também a vontade orientada ao sentido. (Frankl, 1991b, p. 120).

Conscientizando-se a pessoa da questão do sentido, o qual é realizado pela concretização de valores, cria-se 
uma responsabilidade para o ser humano, o que Frankl marcava como um dever-ser (Frankl, 1978, p. 198). Outra diferença entre as três escolas, também se pode ver assinalado quando Frankl cita Hofstatter: "cada uma das três entidades psíquicas encontrou seu advogado entre os terapeutas - o id em Freud, o ego em Adler, o superego em C. G. Jung, R. Allers, e V. Frankl." (Frankl, 1978, p. 199). Ao comentar esta citação, na mesma página, Frankl considera-a válida, abstraindo-se o jargão psicanalítico. E mais ainda, ao trazer para a psicoterapia, através da logoterapia e da análise existencial, a reflexão sobre a liberdade e a responsabilidade, traz para este campo um poder-ser do ser humano, pois a liberdade lhe abre possibilidades que podem ou não ser concretizadas.

Já em 1950, na conferência Sobre Psicoterapia, para neurologistas e psiquiatras austríacos, Frankl assinalava a necessidade de agregar à visão de homem uma dimensão mais além das dimensões física e psíquica, lembrando que apesar de o homem ser uma unidade físico-psíquica "esta unidade não constitui o homem total; precisamente o espiritual é que institui, funda e garante a totalidade do homem" (Frankl, 1991b, p. 117). Frankl estava advogando pelas propostas de Max Scheler e sua teoria dos valores, em que é reservado um lugar especial ao homem no universo (Scheler, 1984). Frankl admite que "a logoterapia é o resultado de uma aplicação dos conceitos de Max Scheler à psicoterapia” (Frankl, 1970, p. 10).

A dimensão espiritual não era ignorada por Freud, apesar de não ser entendida e aceita com a amplitude e a singularidade com que Frankl o fazia. Assinala Frankl: "Freud foi suficientemente genial para ser consciente das limitações do seu sistema, como quando confessou a Ludwig Binswanger que se havia 'sempre limitado', em seu caso, 'ao andar térreo e ao porão do edifício"' (Frankl, 2001, p. 32). Escusado dizer o que Frankl assinalou à exaustão, que espiritual não significa religioso, chegando a propugnar um outro nome - dimensão nooética para sua proposta antropológica, buscando evitar esta confusão conceitual.

Apesar de marcar suas divergências com a Psicanálise e a Psicologia Individual, não se deve pensar que Frankl esquecia as contribuições destas grandes escolas. Veja-se o que ele afirma nas primeiras linhas, do primeiro parágrafo, de seu primeiro livro escrito, publicado em 1946:

Como falar de psicoterapia sem citar os nomes de um Freud e um Adler? Seria impossível, com efeito, tratar de um problema de psicoterapia sem tomar como ponto de partida a psicanálise e a psicologia individual e sem fazer constante referência a eles. Pois não é em vão que se trata dos dois únicos grandes sistemas no campo psicoterápico. Não é possível apagar mentalmente da história da psicoterapia a obra de seus criadores, obra que podemos qualificar de histórica no melhor sentido da palavra, porém também no sentido do que já passou à história, ou seja, do que foi superado e ultrapassado pelo curso ulterior dos acontecimentos (Frankl, 1967, p. 11).

Vemos que Frankl presta, nas linhas acima, uma grande homenagem a seus primeiros mestres, mas não deixa de assinalar a necessidade de prosseguir a caminhada. Sem tirar o mérito das contribuições de Freud e Adler, ele segue sua homenagem, mas lembra também a obrigação de ir além disto ao citar, nesta mesma página, a atitude de Stekel com relação a Freud, de que "um anão sobre os ombros de um gigante pode dominar um campo visual maior que o gigante mesmo" (Frankl, 1967, p. 11). Ao referir-se a estas importantes contribuições dizia que “temos o dever de voltar o olhar para elas", ressaltando, contudo, que "também temos o direito de delas nos afastarmos" (Frankl, 1991b, p. 116).

Frankl marca as limitações que percebe nas visões de ser humano destes grandes mestres:

(...) a neurose, para a psicanálise, representa em última instância uma limitação do eu enquanto consciência, e, para a psicologia individual, uma limitação do eu enquanto responsabilidade (...). Tanto a psicanálise como a psicologia individual vêem, portanto, somente um dos dois lados do ser-homem, um dos fatores da existência humana (Frankl, 1967, pp. 12-13).

Nesta mesma passagem, Frankl assinala o que já era, e continuaria a ser, a base de seu trabalho futuro:

(...) a consciência e a responsabilidade constituem precisamente os dois fatos fundamentais da existência humana. O qual, traduzido numa forma antropológica fundamental, podia expressar-se assim: ser-homem equivale a ser-consciente-e-responsável (...) são os dois aspectos juntos e combinados que oferecem a imagem total e verdadeira do homem (Frankl, 1967, p. 13).

\section{Filosofia e Antropologia como Bases da Psicotera- pia}

"A tese que nos serviu de ponto de partida: Ser homem é ser livre e ser responsável” (V. E.

Frankl)

Frankl, por ser neurologista e psiquiatra, tinha muito presente as dimensões física e psíquica do ser humano, e sua estreita relação - seu paralelismo. Ele tinha também grandes conhecimentos filosóficos, propugnando para o ser humano uma outra dimensão "com um âmbito independente, próprio e que tem suas próprias leis” (Frankl, 1991a, p. 117), capaz de, por meio da "capacidade de oposição do espírito", antagonizar-se com o que se pode denominar a dimensão psicofísica. A logoterapia afirma que esta antagonização é possível mesmo em vivências 
de sofrimento e na proximidade da morte, por meio do valor de atitude (Kroeff, 1998; 2000a). É compreensível, então, que Frankl visse na filosofia e na antropologia as bases da sua psicoterapia. Considerem-se as frases a seguir: "Não há psicoterapia sem uma teoria do homem e uma filosofia de vida embasando-a. Intencionalmente ou não intencionalmente, a psicoterapia é baseada nelas" (Frankl, 1970, p. 15); e "As implicações clínicas da logoterapia derivam-se, na verdade, de suas implicações antropológicas" (Frankl, 1970, p. 99).

Frankl não podia ser mais claro e explícito: é na imagem de homem e na sua filosofia de vida que temos a chave para a psicoterapia. E sobre isto, veja-se o que oferece a logoterapia: "O conceito de homem da logoterapia está baseado em três pilares, a liberdade da vontade, a vontade de sentido, e o sentido da vida" (Frankl, 1970, p. 16). Assim, Frankl afirma a capacidade do homem de resistir ao pan-determinimo, ao mesmo tempo em que exerce com responsabilidade a sua liberdade, tendo como motivação primária e básica o desejo de encontrar sentidos, os quais são alcançados pela realização de valores. Sua proposta de imagem de homem afastase das visões biologistas, psicologistas e sociologistas, pois, como diz Fizzotti, "estas esforçam-se por reduzir o homem a um esquema demasiado simples: instinto, autômato com simples reflexos, mecanismo anímico, resultado de forças produtivas e econômicas" (Fizzotti, 1981, p. 42). Não é uma questão de negar estas forças, mas de não supervalorizá-las:

O logoterapeuta não esquece a condição psíquica e psico-física do homem, sua estrutura pulsional, a importância da infância, do ambiente e do que aprendeu no passado. Porém, completa este esquema antigo afirmando no homem uma dimensão espiritual; dentro desta dimensão, o homem pode fixar uma tarefa por si mesma, e não para resolver suas tensões internas, pode realizar esta tarefa porque a considera justa e importante, e não porque lhe permite satisfazer seus desejos ou diminuir o peso de suas aspirações sociais. A logoterapia, portanto, substitui a fórmula nihilista de que o homem 'é somente' (um animal mais evoluído, um produto do acaso...) pela fórmula positiva de que o homem é 'muito mais do que'... (Lukas, s/d, p. 52).

\section{Logoterapia Versus Psicoterapia}

“(...) análise existencial. O que não quer é suplantar as psicoterapias anteriores: quer somente chegar mais alto, agregar-lhes algo" (Frankl, 1991b, p. 121)

O título desta seção e sua epígrafe, já trazem a temática que aqui vai ser abordada. Pode-se legitimamente fazer esta contraposição da logoterapia com a psicoterapia? Há momentos, em seus escritos, que Frankl afirma claramente um caráter complementar à logoterapia. Veja-se o que diz em seu livro Homo patiens - projeto de uma patodicéia:

(...) a logoterapia se situa (...) no que concerne à doutrina, em uma oposição didática à psicoterapia, tal como esta tem sido praticada até hoje. Não pretende, contudo, ser um substituto da psicoterapia, no sentido estrito do termo. É impossível colocar a logoterapia no lugar da psicoterapia; é necessário, apenas, complementar a psicoterapia com a logoterapia (Frankl, 1978, pp. 198-199).

Isto também é explicitado em outra citação, ao atribuir à análise existencial - um dos nomes iniciais da logoterapia - que "o que não quer é suplantar as psicoterapias anteriores: só quer chegar mais alto, agregarIhes algo [...]"(Frankl, 1991b, p. 121). O título em inglês do seu primeiro livro escrito - The doctor and the soul: From psychotherapy to logoterapy (Frankl, 2001, p. 59) também induz à idéia de que logoterapia e psicoterapia se contrapõem, dando uma idéia de transição, "da psicoterapia para a logoterapia".

Mas, então, o que é logoterapia? Não é a logoterapia também uma psicoterapia? Para responder a esta pergunta, há que se fazer uma diferenciação quanto ao tipo de neurose que apresenta o paciente. Segundo Frankl, "o que necessita o paciente colhido no desespero existencial do aparente sem-sentido de sua vida é logoterapia em vez de psicoterapia" (Frankl, 1970, p. 99). Pode-se ver aqui que Frankl é claro: nos pacientes com neurose noogênica - uma das propostas originais de Frankl -, na qual a pessoa convive por muito tempo com uma sensação de vazio existencial, ou com conflitos de valores, ou com a descrença no sentido da vida, ou com a impossibilidade de sua realização, a logoterapia é diferente de psicoterapia. Diz ele: "A finalidade do que chamamos de logoterapia é incluir o logos na psicoterapia; a finalidade do que denominamos análise existencial é incluir a existência na psicoterapia" (Frankl, 1978, p. 197). Na mesma página desta citação, é explicado o que significa incluir estes elementos na psicoterapia: o logos estaria introduzindo na psicoterapia uma reflexão sobre o sentido e os valores; a existência traria a este campo de atuação do psicoterapeuta uma reflexão sobre a liberdade e a responsabilidade. Numa época em que se considerava serem estes elementos estranhos ao atuar psicoterapêutico, ou no mínimo, não centrais, a logoterapia vinha oferecer ao ser humano necessitado a sua terapêutica específica. Não nos esqueçamos de que Freud, em carta à princesa Bonaparte, via a preocupação com o sentido da vida como uma manifestação de doença, o que contrasta radicalmente com Frankl, que vê nesta preocupação uma manifestação de saúde do ser humano. 
Ao lidar com neuroses psicogênicas, contudo, não existe esta contraposição entre logoterapia e psicoterapia: "Aqui a logoterapia não pode ser contraposta à psicoterapia, representando ela mesma uma entre as escolas de psicoterapia." (Frankl, 1970, p. 99). Apesar disto, Frankl não deixa de assinalar, que no seu elemento plus - o sentido e a existência - a logoterapia deveria ser um complemento para qualquer psicoterapia.

\section{Logoterapia como Psicoterapia: o "Que" e o "Como"}

"Depende, a priori, menos de uma exposição do "was" (que) da Psicoterapia em sua totalidade, e mais de uma introdução no “wie” (como) (Frankl, 1976, p.

XIV).

Talvez uma das lacunas da qual se ressintam os logoterapeutas é quanto a como deve atuar o terapeuta em sessões de logoterapia. Frankl não deixou nenhum escrito no qual esta questão seja trabalhada sistemática e exaustivamente. Defendendo que o terapeuta deveria ser criativo e capaz de improvisar, além de se ajustar às diversas situações e casos que estavam sendo tratados, Frankl acreditava que "uma psicoterapia de tal ordem, propiciadora, ao que parece, de um processo de individualização, não é passível de ser ensinada, pelo menos de forma total" (Frankl, 1976, p. XII). Não quer dizer que Frankl, assim como outros autores, não tenham mencionado muitas vezes suas formas de atuar. Nesta seção, pretende-se apresentar algumas orientações, principalmente de Frankl, sobre objetivos e condução de sessões de logoterapia.

Uma das mais conhecidas passagens dos livros de Frankl é aquela na qual ele responde a um paciente, que depois de lhe dar uma fórmula concentrada do que seria a psicanálise - deitar e contar coisas desagradáveis de se contar - solicitava a Frankl uma explicação, em uma frase, do que seria a logoterapia. A resposta de Frankl: "Bem, na logoterapia o paciente pode ficar sentado normalmente, mas precisa ouvir certas coisas que às vezes são muito desagradáveis de se ouvir" (Frankl, 1991a, p. 91). Logo a seguir, Frankl reconhece que sua resposta simplifica demais as duas escolas, mas admite que há elementos que podem ser comparados e diferenciados entre as duas, a partir das fórmulas concentradas. Já que para a psicanálise os problemas do indivíduo estão muito conectados aos embates entre suas instâncias psíquicas internas e a elementos anteriormente reprimidos por este indivíduo, nada mais lógico que ela ser bastante introspectiva e retrospectiva, ou seja, centrar-se no interior do próprio indivíduo e nos elementos reprimidos no passado, que devem ser re-elaborados, ao serem retornados à consciência. Já a logoterapia, por centrar-se na questão do sentido a ser realizado, o qual está no futuro, tenderia a ser mais prospectiva do que retrospectiva, ou seja, mais focada na dimensão futura. Além disso, ao afirmar que os sentidos a realizar estão no mundo e no encontro com os outros, e não em si mesmo, ressalta que o indivíduo deve ir além de si mesmo para realizar os sentidos - a característica humana de auto-transcendência -, a logoterapia teria que ser menos introspectiva. Ao buscar conscientizar o indivíduo do valor central que tem o sentido e os valores em sua vida, se está orientando o paciente mais para seu futuro do que para seu passado. Também, ao combater círculos viciosos derivados de excessiva introspecção - ou em termos logoterapêuticos, de hiper-reflexão e hiper-atenção - que teriam um papel determinante na gênese de muitos distúrbios neuróticos, teria que ser menos introspectiva, menos voltada para um auto-centramento.

Frankl deixa claro que sua resposta ao paciente, mencionada anteriormente, foi "uma brincadeira, sem a intenção de fornecer uma fórmula concentrada da logoterapia", e que "esta formulação simplifica demais as coisas", mas que "não deixa de ter sua razão." (Frankl, 1991a, p. 91). Estas considerações de Frankl buscam evitar mal entendidos, sobre a ênfase que ele vê ser colocada, nas duas escolas, às direções retrospectiva ou prospectiva, ao centramento no indivíduo ou no outro e no mundo, no passado ou no futuro, e no que deve ser conscientizado, e não numa negação do eventual valor do elemento contraposto.

Guilhermo Pareja Herrera, autor de uma obra fundamental sobre Frankl e a logoterapia (Herrera, 1987), no primeiro curso de formação sobre logoterapia promovido no Brasil, disse que não havia ditames específicos quanto ao "como" devia atuar o logoterapeuta numa sessão clínica, mas que havia sim especificações sobre o conteúdo que devia ser trabalhado. Explicitou isto dizendo: "Quem me ensinou como fazer foi Rogers, mas quem me ensinou o que fazer foi Frankl"2. Ao sentir-se liberado para usar um método de atuação de outra escola, Herrera estava afirmando algo que Frankl sempre teve muito presente: o caráter extremamente dinâmico do atuar psicoterapêutico e as muitas variáveis que tornam impossível uma normatização acabada para esta tarefa. Contudo, Frankl deixava claro o que devia fazer o terapeuta: "O papel do logoterapeuta consiste em ampliar e alargar o campo visual do paciente de forma que todo o espectro do significado e dos valores se torne consciente e visível para ele" (Frankl, 1977, pp. 173-174).

Frankl cita um autor de peso ao advogar pela necessidade de levar em conta a individualidade do terapeuta. Vale a pena conhecer a citação na íntegra, como um antídoto para a rigidez metodológica:

\footnotetext{
2 Anotações de uma das etapas do "Curso de Formação em Logoterapia”, realizado pela Sociedade Brasileira de Logoterapia (SOBRAL), em Porto Alegre, RS, em 1987.
} 
Um psicanalista uma vez falou sobre o seu tipo de terapia: "Esta técnica provou ser o único método adequado à minha individualidade; eu não ouso negar que um médico constituído de forma bastante diferente poderia se sentir impelido a adotar uma atitude diferente com relação a seus pacientes e à tarefa que tinha pela frente". O homem que fez esta confissão foi Sigmund Freud (Frankl, 1970, p. 110)

Considerando-se a afirmação de Frankl de que o método psicoterapêutico deve ser modificado de acordo com a individualidade do paciente e a personalidade do terapeuta, levando-se em conta também a situação específica que se está trabalhando no momento, sua recomendação não poderia ser outra a não ser que "nunca se deve esquematizar, o essencial é improvisar e individualizar" (Frankl, 1978, p. 200). Segundo ele, nenhum método de psicoterapia - inclusive, obviamente, a logoterapia pode pretender ser aplicado a qualquer paciente, obtendo sempre o mesmo grau de sucesso. Há que se considerar também a habilidade que o terapeuta possui. Segundo Frankl (1970, p. 108):

[...] o método de escolha em um determinado caso é como uma equação com duas incógnitas [...] A primeira incógnita representa a personalidade singular do paciente. A segunda incógnita representa a personalidade singular do terapeuta. Ambas devem ser levadas em conta antes de que um método de psicoterapia seja escolhido.

O que realmente importava, Frankl não perdia de vista: "mais e mais a relação EU-TU pode ser vista como o centro da questão" (Frankl, 1970, p. 8). Frankl criou diversas técnicas, mas ele é conhecido principalmente, mesmo entre psicoterapeutas que não conhecem a logoterapia, pela técnica da Intenção Paradoxal. As técnicas não o desviaram do foco a ser mantido, pois para ele "o que importa em terapia não são as técnicas, mas sim as relações humanas entre o doutor e o paciente, ou o encontro pessoal", chegando inclusive a afirmar que "um enfoque puramente tecnológico à psicoterapia pode bloquear seu efeito psicoterapêutico" (Frankl, 1970, p. 6). Frankl busca na antiguidade grega um modelo psicoterápico: “(...) toda psicoterapia, em particular a logoterapia, deve ter por base, e como modelo, o clássico diálogo socrático da conversa entre dois seres humanos." (Frankl, 1976, p. XI)

Elisabeth Lukas, uma das mais conhecidas seguidoras de Frankl, dizia que nós, "os psicoterapeutas temos que improvisar, experimentar, investigar: na logoterapia não há padrões fixos" (Lukas, s/d., p. 210). Lukas é também uma das logoterapeutas que mais se preocupou em oferecer orientações mais sistemáticas e organizadas dos ensinamentos de Frankl, que pudessem servir de guia para o logoterapeuta. Ela oferece um roteiro para o pla- no de tratamento, composto de quatro fases: autodistanciamento, mudança de atitude, redução dos sintomas, orientação para o sentido. Explica ela:

Caso se tenha relaxado a estreita união entre o paciente e o sintoma mediante o distanciamento (primeira fase) e construído atitudes novas e positivas com relação aos fatores negativos imodificáveis (segunda fase), muitas vezes os sintomas se reduzem por si mesmos (terceira fase), e só falta descobrir os fatores positivos que podem preencher a situação pessoal e atual (quarta fase). (Lukas, s/d, p. 167).

Lukas, contudo, lembra que este é somente um plano esquemático, que não se pode pretender aplicar a todos os casos. Quando está envolvida a tríade trágica - culpa, sofrimento e morte - ela adverte que o imodificável destes elementos "são a barreira externa na qual chegam a seu limite nossos métodos e possibilidades" (Lukas, s/d. p. 149). E completa:

Aqui já não se dá um autodistanciamento dos sintomas (quem poderia distanciar-se da dor, da culpa e da morte?); aqui já não se dá uma redução dos sintomas (quem poderia desfazer o feito?); porém sempre se dá a escolha de uma atitude frente a eles (segunda fase) e sempre se dá o desenvolvimento de outras possibilidades intactas de sentido (quarta fase) (Lukas, s/d, p. 149)

Assim, mesmo ante a referida tríade trágica, a logoterapia tem contribuições a oferecer ao ser humano (Kroeff, 2002, 2007). Lukas oferece também outras orientações muito claras do atuar psicoterapêutico, dando permissão para que o terapeuta seja "capaz de dizer 'não', um 'não' muito decidido, quando o paciente se sente dependente de determinantes infelizes que impedem o desenvolvimento de sua personalidade" (Lukas, s/d, p. 156). Ela discorda de atuações simplesmente reflexivas do terapeuta, que se guarda de expressar quaisquer opiniões. Na verdade, libera o logoterapeuta para intervir:

O logoterapeuta, pelo contrário, intervém pessoalmente na conversação e inclusive apresenta uma oposição saudável, quando é necessária. Diz 'não' ao neurótico obsessivo: 'Não, não vais fazer isto que te dá medo; pode estar seguro de que não vai acontecer!'. Diz 'não!' ao depressivo: 'Não, não é verdade que tua vida careça de valor e de sentido; vou te demonstrar isso!'. A logoterapia ensina que uma falsa compreensão e um simples reflexo dos problemas apresentados aprisionam cada vez mais neles, o paciente. Se um paciente vem e afirma que a vida já não lhe proporciona nenhuma alegria, um logoterapeuta não dirá nunca: 'Queres dizer, então, que não desejas continuar vivendo, que queres morrer?' (reflexo), nem tampouco: 'Compreen- 
do-o muito bem depois de tudo pelo que passaste...' (compreensão), mas dirá talvez: 'E as tarefas da vida que lhe aguardam?' (Lukas, s/d, p. 155-156).

Deve-se também atentar para as orientações de Fizzotti, outro logoterapeuta, quando diz que “(...) um dos elementos centrais no sistema terapêutico de Frankl [é] a atitude positiva e ativa do logoterapeuta" (Fizzotti, 1981, p. 227-228).

Estas orientações de Lukas e Fizzotti podem levar a mal-entendidos. Não há uma pretensão de moralizar ou interferir na liberdade do paciente, pois, como diz Frankl:

A logoterapia busca tornar o paciente completamente consciente de sua própria responsabilidade; por isso precisa deixar que ele opte pelo que, para que ou perante quem ele se julga responsável. Eis porque um logoterapeuta é, dentre todos os psicoterapeutas, o que menos se vê tentado a impor julgamentos de valores a seus pacientes, porque jamais permitirá que o paciente transfira ao médico a responsabilidade de julgar (Frankl, 1977, pp. 173-174).

\section{Psicoterapia: Campo de Cooperação e Ecletismo}

Fizzoti (1981) declara:

[A] logoterapia não é um sistema fechado, como rocha inexpugnável e inatacável. É uma orientação de busca e, portanto, está fundamentalmente aberta numa dupla perspectiva: a da cooperação ativa com outras diretrizes psicoterapêuticas e a da evolução interna de si mesma. Isto representa uma atitude de diálogo com todas as demais escolas de psicoterapia, das quais a logoterapia espera receber úteis indicações para seu aperfeiçoamento ulterior (...) (p. 249).

Frankl não pretendia que a logoterapia fosse uma panacéia ou que servisse para todas as situações, ou a todos os pacientes, declarando, portanto, que "não pode haver objeções de combiná-la com outros métodos" (Frankl, 1970, p. 110). Dentre estes métodos, entre outros, citava a hipnose, o treinamento em relaxação, a terapia comportamental e a farmacoterapia. Nesta mesma linha de raciocínio, dizia Lukas: “(..) o bom da logoterapia é que suas formas de tratamento, inerentes ao sistema, podem combinar-se perfeitamente com outras modalidades terapêuticas" (Lukas, s/d, p. 85).

Considerando que a psicoterapia é um campo muito vasto de estudo, propunha Frankl: "para a investigação vale o mandato da cooperação; porém, para a prática vale algo mais: vale o mandato do procedimento consciente eclético" (Frankl, 1991b, p. 121). Ao propugnar por "um ecletismo consciente" não deixa Frankl de recomendar "muito cuidado, porém, para que o ecletismo não degenere em sincretismo" (Frankl, 1978, p. 201). Apesar das propostas de possível cooperação entre as escolas psicoterapêuticas e de ecletismo, não deixava Frankl de advertir que "nem todo psicoterapeuta é capaz de tratar segundo qualquer método, [...] qualquer método não pode ser aplicado a todo caso e a todo paciente" (Frankl, 1991b, p. 122), pois a psicoterapia "pressupõe um respeito sem limites pela unicidade e singularidade de toda existência humana" (Frankl, 1991b, p. 129).

\section{Considerações Finais}

A psicoterapia é um campo com múltiplos sistemas e propostas de atuação. Este artigo apresentou uma visão da psicoterapia, segundo a logoterapia, a qual poderia ser classificada como de orientação humanista-existencial.

Na logoterapia, o ser humano é conceptualizado como um ser livre, capaz de tomar consciência desta liberdade, e de agir responsavelmente, motivado pelo que considera os sentidos de sua vida. Quando o sentido de vida não está presente na vida da pessoa, esta pode experienciar um vazio existencial. A logoterapia visa ampliar a capacidade da pessoa de perceber todas as possibilidades existentes de sentido em sua vida, escolhendo para realizar aquelas que considera mais significativas. Não há um sistema padronizado sobre como conduzir sessões de psicoterapia, mas são dadas orientações, a partir da concepção filosófica da logoterapia, baseada principalmente em Max Scheler, e no atuar psicoterapêutico de logoterapeutas, principalmente de Viktor Frankl e Elisabeth Lukas.

Lukas, ao assinalar o fato de que a psicoterapia tem que abarcar todas as dimensões do ser humano, conclui que isto "implica nada menos que a obrigação [...] de que o psicoterapeuta se ocupe também do sentido" o que demonstraria, além de sua natureza como terapia específica ou concorrente entre outras psicoterapias, "o caráter complementar da logoterapia” (Lukas, s/d, p. 73). A logoterapia pretendeu ampliar o que devia ser considerado no estudo das neuroses, incluindo "as categorias dos valores e do sentido" (Frankl, 1991b, p. 118), o que implica em incluir a dimensão antropológica espiritual do ser humano, transformando a díade de estudo "herança e ambiente", num tripé que inclui "a pessoa que escolhe livremente", acrescentando que "não pode bastar-Ihe à psicoterapia de hoje capacitar ao homem para gozar ou trabalhar: tem que capacitá-lo em certo sentido, para sofrer" (Frankl, 1991b, p. 127), já que o sofrimento é elemento inescapável da existência (Kroeff, 2000b).

Por tudo que foi exposto, percebe-se que a logoterapia, à medida do seu desenvolvimento e ampliação, evoluiu de uma proposta inicial de complemento à psicoterapia, para ser a terapia específica nos casos de neurose noogênica, avançando para ser também uma escola de 
psicoterapia entre outras, chegando por fim, a apresentar-se como possibilidade de um complemento para as outras psicoterapias.

\section{Referências}

Fizzotti, E. (1981). De Freud a Frankl - Interrogantes sobre el vacio existencial. Pamplona: Eunsa.

Frankl, V. E. (1967). Psicoanálisis y existencialismo. México: Fondo de Cultura Económica.

Frankl, V. E. (1970). The will to meaning. New York: The New American Library.

Frankl, V. E. (1976). Psicoterapia - Uma casuística para médicos. São Paulo: E.P.U.

Frankl, V. E. (1977). Man's search for meaning. New York: Pocket Books.

Frankl, V. E. (1978). Fundamentos antropológicos da psicoterapia. Rio de Janeiro: Zahar.

Frankl, V. E. (1983). Psicoterapia y humanismo. Madrid: Fondo de Cultura Económico.

Frankl, V. E. (1991a). Em busca do Sentido - Um Psicólogo no Campo de Concentração. São Leopoldo: Sinodal / Petrópolis: Vozes.

Frankl, V. E. (1991b). La voluntad de sentido. Barcelona: Herder.

Frankl, V. E. (2001). Psicoterapia y existencialismo. Barcelona: Editorial Herder.

Herrera, G. P. (1987). V. E. Frankl - Comunicación y Resistencia. México: Premi Editora.
Kroeff, P. (1998). Consideraciones sobre el valor de actitud en logoterapia. Nous - Boletín de Logoterapia y Análisis Existencial (Madrid), 2, pp. 39-45.

Kroeff, P. (2000a). Otra faceta de la enfermedad y de la muerte. Nous - Boletín de Logoterapia y Análisis Existencial (Madrid), 4, pp. 43-63.

Kroeff, P. (2000b). Afrontando la enfermedad y la muerte: Una investigación en pacientes con cáncer. Tese de doutorado não publicada, Facultad de Psicologia, Madrid, Espanha.

Kroeff, P. (2002). Sentido de vida y reacciones al cáncer. Revista Mexicana de Logoterapia, 7, pp. 30-49.

Kroeff, P. (2007). Logoterapia, sentido de vida y la tríada trágica: sufrimiento, culpa y muerte. Revista Mexicana de Logoterapia, 19, pp. 16-24.

Lukas, E. (s/d). Tu vida tiene sentido - Logoterapia y salud mental. Barcelona: Claves.

Scheler, M. (1984). El puesto del hombre en el cosmos. Buenos Aires: Editorial Losada.

Paulo Kroeff - Psicólogo. Psicoterapeuta. Especialista em Terapia de Casal e Família. Mestre em Educação. Doutor em Psicologia. Professor Adjunto IV, Aposentado, da Universidade Federal do Rio Grande do Sul. Endereço Institucional: Universidade Federal do Rio Grande do Sul, Departamento de Psicanálise e Psicopatologia, Instituto de Psicologia. Rua Ramiro Barcelos, no 2600 (Santana) - CEP: 90.035-003 - Porto Alegre-RS.Email: kroeff.paulo@yahoo.com.br

Recebido em 12.11.2010 Primeira Decisão Editorial em 20.05.2011 Aceito em 30.06.11 